\title{
Hydraulic behavior of subsidence-induced surface discontinuities in the hydrogeology of the Aguascalientes valley
}

\author{
Lilia Guerrero-Martínez ${ }^{1}$, Martín Hernández-Marín ${ }^{2}$, and Ángel Eduardo Muñoz-Zavala ${ }^{3}$ \\ ${ }^{1}$ Departamento de Geotecnia e hidráulica, Universidad Autónoma de Aguascalientes, \\ Aguascalientes, Ags. 20131, México \\ ${ }^{2}$ Departamento de Geotecnia e hidráulica, Universidad Autónoma de Aguascalientes, \\ Aguascalientes, Ags. 20131, México \\ ${ }^{3}$ Departamento de Estadistica, Universidad Autónoma de Aguascalientes, \\ Aguascalientes, Ags. 20131, México
}

Correspondence: Lilia Guerrero-Martínez (lilia.guerrero@edu.uaa.mx)

Published: 22 April 2020

\begin{abstract}
The impact of faults and fissures (discontinuities) on the groundwater flow has become important in several parts of the world because the heterogeneous and anisotropic distribution of permeability in fault zones is difficult to characterize. Based on this, we propose an analysis of patterns of parameters measured in groundwater, under the premise that the observed anomalies can be indicators of the hydraulic behavior of the flow in the direction perpendicular to the fault plane. In this context, if the discontinuities are sealed, they behave as hydraulic barriers, causing variation in the continuity of the parameters across the fault plane. Conversely, when faults are a conduit, they appear to have a small or null variation in the distribution of the parameter measurements. The impact of discontinuities in groundwater flow in a zone with a large number of faults and fissures such as that of the Aguascalientes valley is being studied using a graphical-correlation analysis with the revision of 230 wells, through the measurement of parameters such as temperature and static levels across discontinuities, in order to determine the hydraulic behavior of the faults. This investigation considered values over $4{ }^{\circ} \mathrm{C}$ for geothermal variations and $10 \mathrm{~m}$ for hydraulic-head changes to define fault behavior. Results show three zones through mapping analysis, where the fault presents barrier behavior and where the hanging block represents high values; these anomalies are much higher than the average across the valley and indicate the propensity for the fault to restrict horizontal flow. In conclusion, the Oriente fault presents complex behavior of a barrier-conduct system along the fault. This analysis gives a robust way to describe fault behavior without referring to elaborate and invasive hydrological investigations.
\end{abstract}

\section{Background}

In general, in areas with the presence of active surface discontinuities, the permeability of the fault zone (the zone mechanically affected by the discontinuity) is usually different to that of the host rock. For instance, studies of hydrocarbon reservoirs have shown that individual fault zones can act as a seal for underground flow in some areas, delaying movement of the fluid, but in other zones they can behave as a conduit to fluid flow across the fault plane. In general, this vari- able behavior is the result of a complex function of host rock lithology, fault dynamics and weathering processes; therefore, fault zones are heterogeneous structures that cannot simply be defined as barriers or conduits for fluid flow in space or time (Haneberg, 1995; Yielding et al., 1999).

In particular, the hydraulic behavior of a fault zone will depend on different factors, such as the percentage of clay within the fault core (Apaydin, 2010), the structures of the damage zone which is defined as an area with densely frac- 


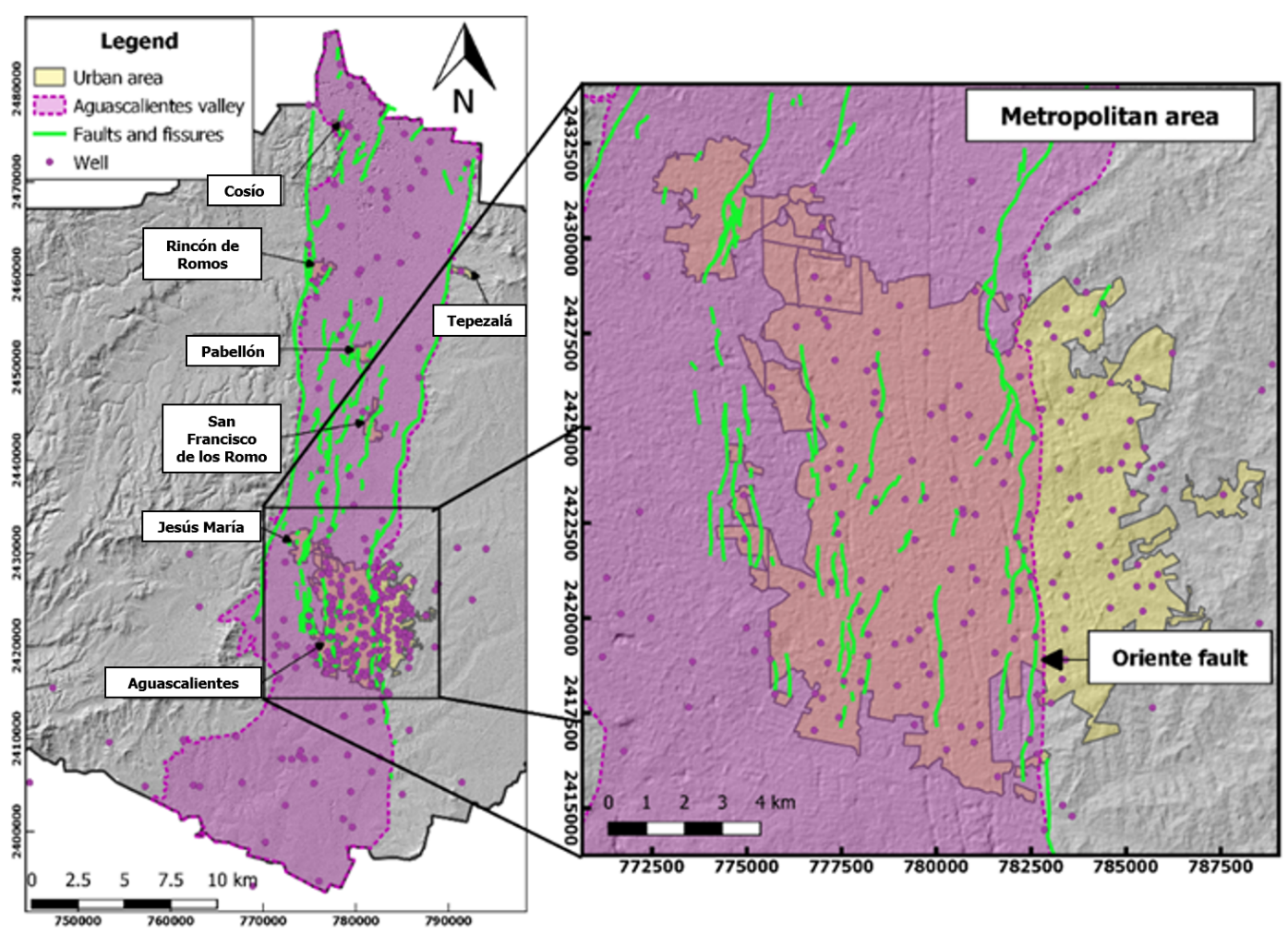

Figure 1. System of faults and fissures and the location of production wells for the Aguascalientes valley (SIFAGG, 2017; Conagua, 2017).

tured rocks in the vicinity of the fault, which can greatly improve permeability and consequently the flow of fluid through the area's (Caine et al., 1996) activity or inactivity, the age, the potential dissolution or precipitation of chemical substances transported by the flowing water, and the stress regime to which the structure is subjected (Hernández-Marín and Burbey, 2009; Hernández-Marín et al., 2017). However, these factors that define a particular hydraulic fault's response are difficult to quantify. One of the techniques that provide qualitative elements for defining the hydraulic behavior is the mapping of parameters measured in the groundwater, which can reveal anomalous variations across a fault zone. For instance, recent investigations in predicting the hydraulic properties of the fault zone are employed by different investigators (i.e., Bense et al., 2003, 2008; Anderson and Fairley, 2008), in which the authors based their research on the elaboration of detailed profiles. These profiles show anomalies of the hydraulic heads and geothermal variations. These investigations employ critical values of $4{ }^{\circ} \mathrm{C}$ for geothermal variations and $10 \mathrm{~m}$ for hydraulic heads; the changes define the faults as a barrier or conduct. The analysis of hydraulic-fault response based on graphical representations can give an overview of the hydrological conditions around several faults, where the parameters measured in the groundwater, combined with the available geological information on the area, can better explain the observed variation in the hydraulic properties of failures. The objec- tive of this work was to perform a two-parameter graphicalcorrelation analysis that characterizes the hydraulic behavior of the faults regarding temperature and hydraulic heads. This analysis provides a better understanding of the aquifer system of the Aguascalientes valley.

\section{Description of the study area}

The study area corresponds to the metropolitan area of the state of Aguascalientes, within the valley of Aguascalientes. At present, enormous pressure is on the resources and groundwater, in part due to the semi-arid condition of the valley (Hernández-Marín et al., 2018), the low volume of surface water which is used mostly for agriculture, and the increasing need for municipal and industrial services. This generates problems directly associated with overexploitation including, for instance, the increase of heavy metals in the water due to the extraction of deep-rooted water and the surface deformation observed as subsidence and fracturing (Pacheco-Martínez et al., 2013). The intensive pumping has caused a decrease in water levels, especially under the city of Aguascalientes, favoring the appearance of surface discontinuities. As observed on the maps of fissures and faults periodically published by the local government (SIFAGG, 2017), the discontinuities within the valley are parallel to the western and eastern regional faults (Fig. 1), which are believed 


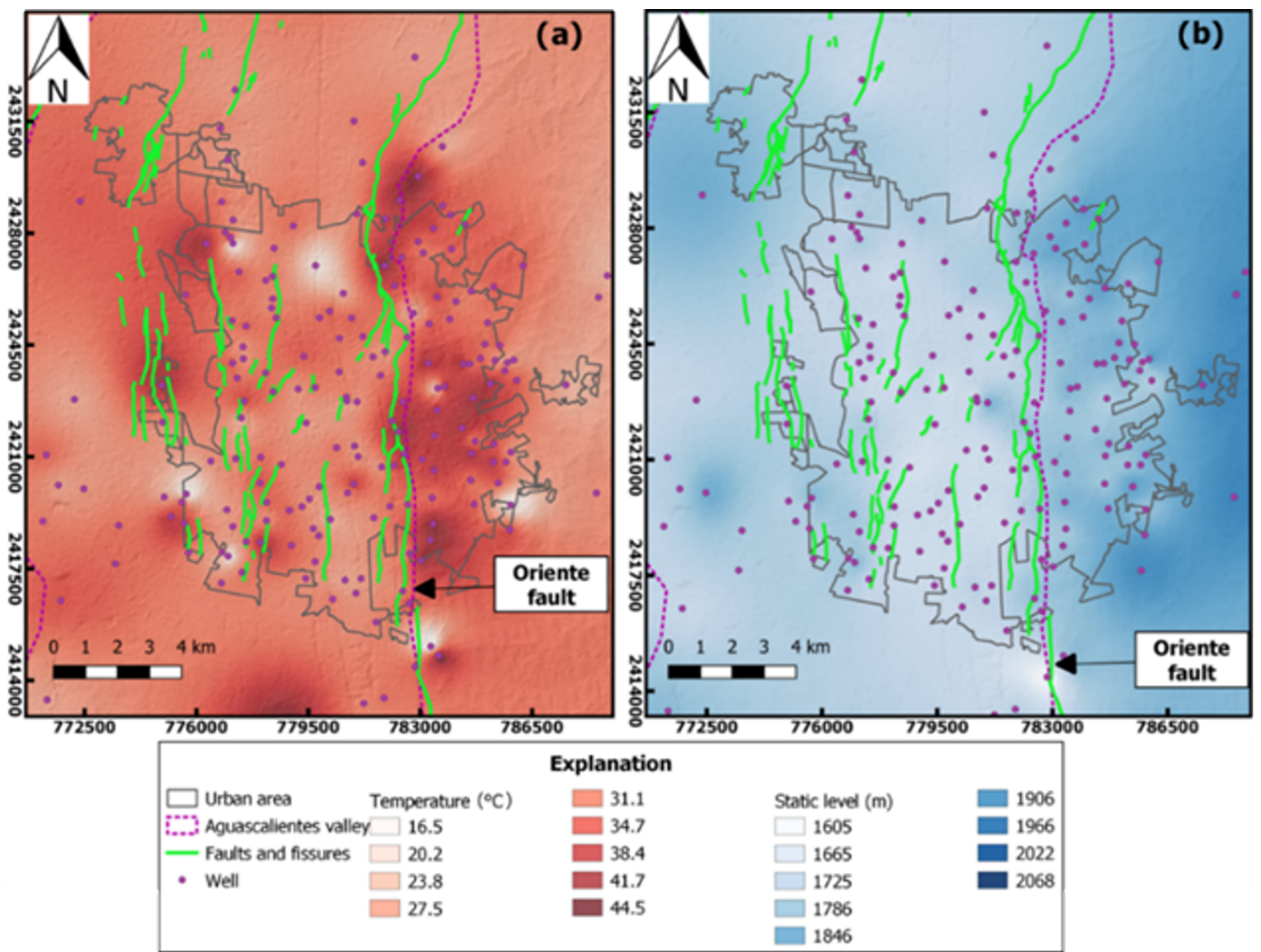

Figure 2. Variation of temperature (a) and groundwater levels (b) within the study area. Faults and fissures are included in the maps.

to participate directly in the origin of graben from Aguascalientes (Pacheco-Martínez et al., 2015).

\section{Methods}

The data of the analysis were obtained from 230 extraction wells for 2017 (Fig. 1), where temperatures and groundwater levels were measured through a probe. These data were analyzed and mapped in order to capture the variation of these two hydraulic properties for particular zones of the fault. The map was later useful in performing a comparative analysis of the variation of these parameters with respect to the location of the analyzed fault. A multilevel $b$-spline interpolation of the measurements was made with a resolution of $20 \times 20 \mathrm{~m}$, as shown in Fig. 2a and b, respectively.

\section{Results}

As shown in Fig. $2 a$ and $b$, the most notable differences in temperature and groundwater levels are observed to the east of the municipality and coincide with the location of the Oriente fault, classified as a normal fault in the Aguascalientes valley, and as observed in the Fig. 2, which has a noticeable impact on the regional groundwater flow. No variation in temperature and groundwater levels were detected across small secondary faults, although we suspect that the variation is more difficult to detect due to the lack of sampling points and the small size of these discontinuities.

The graphical-correlation analysis shows some similarities between Fig. $2 \mathrm{a}$ and $\mathrm{b}$, regarding mapping parameters. These similarities could indicate that the Oriente fault has some areas with characteristics of barrier hydraulic behavior; however, if analyzed in detail, it can be observed that the hydraulic behavior is not the same throughout the length of the fault. As shown in Figs. 3 and 4, three zones were drawn based on temperature and groundwater level variations with respect to the fault. Zones 1 through 3 are considered as hydraulic barriers due to high variations of temperature and groundwater levels observed in these areas with respect to the fault; that is, in these zones, both parameters show anomalies, and hence they have barrier behavior transverse to fluid flow, which on the unmarked areas is considered conduct behavior. In particular, the Fig. 3 shows temperatures vary up $10^{\circ} \mathrm{C}$ across the fault for Zone $1,8^{\circ} \mathrm{C}$ for Zone 2 and $11^{\circ} \mathrm{C}$ for Zone 3; on the other hand, in the area that does not show significant variations, the temperature may indicate conduit behavior.

In the case of the comparison of geothermal anomalies and the Oriente fault, the footwall block of the fault has a higher temperature. 


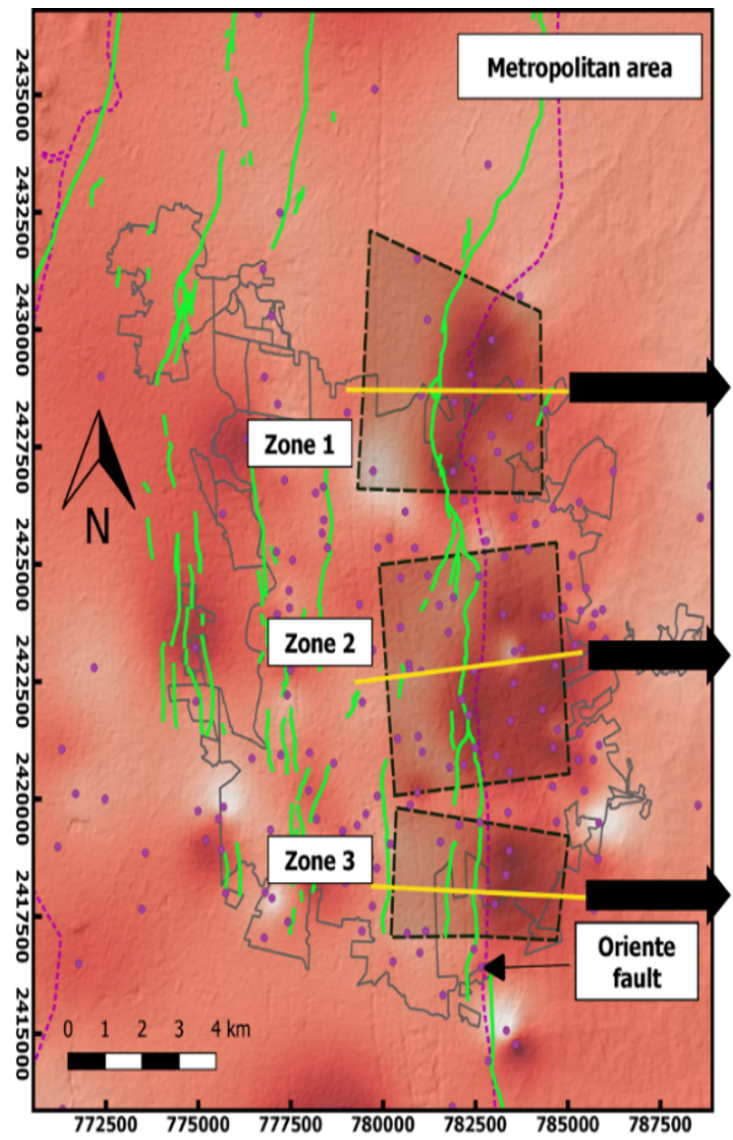

\section{Explanation}

\begin{tabular}{|c|c|c|}
\hline Well & Temperature $^{\circ} \mathrm{C}$ & \\
\hline - Faults and fissures & 16.5 & \\
\hline Temperature $\mathrm{p}$ & 20.2 & \\
\hline & 23.8 & \\
\hline 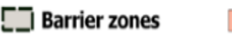 & 27.5 & \\
\hline
\end{tabular}
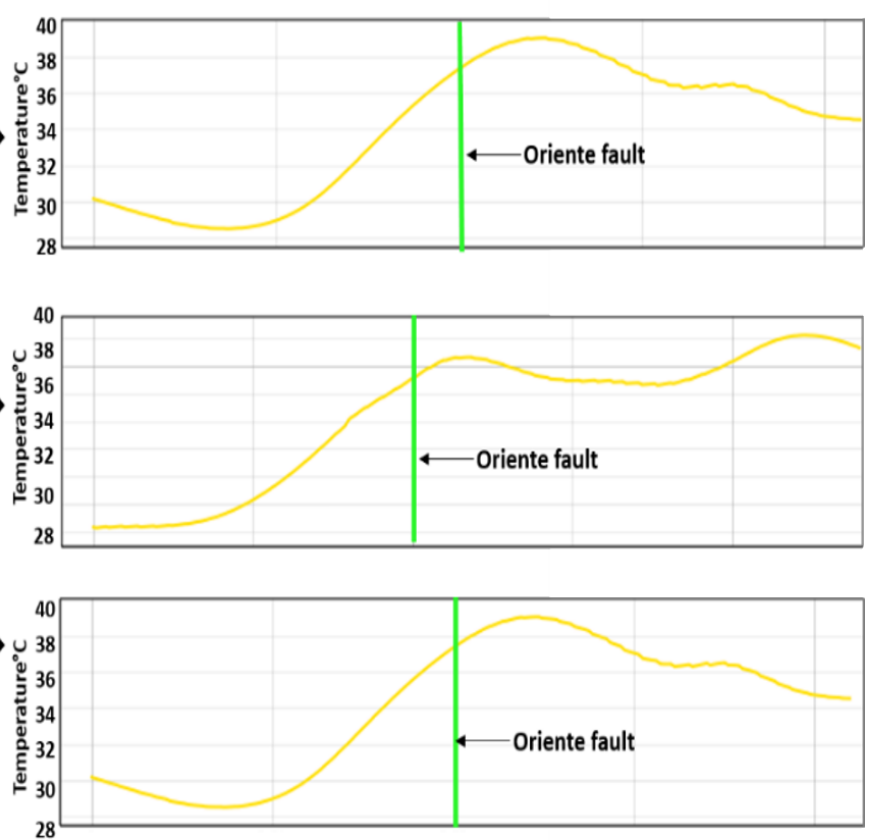

Figure 3. Comparison of geothermal anomalies and the Oriente fault.
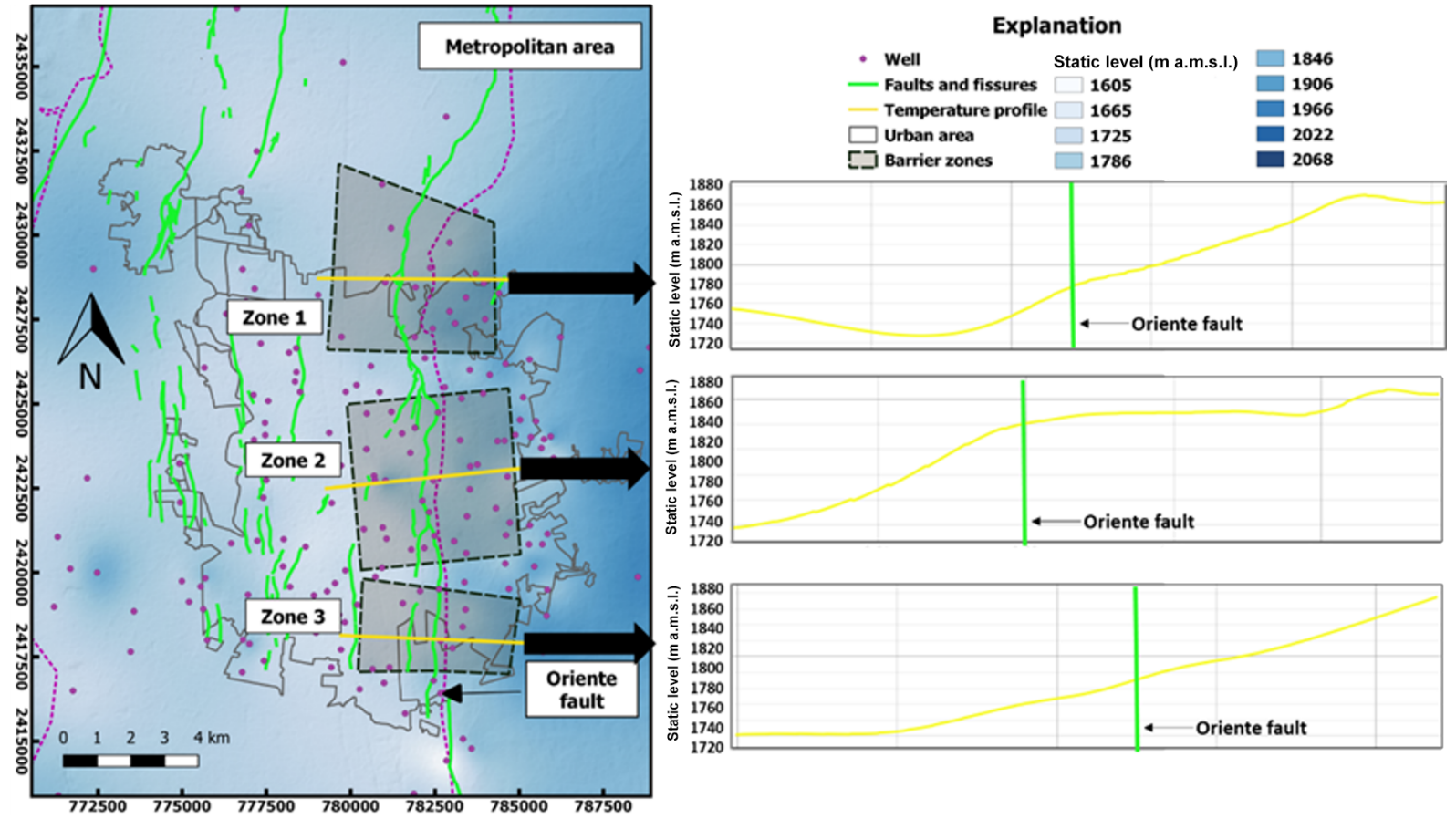

Figure 4. Comparison of hydraulic heads and the Oriente fault. 
The areas with a high variation of temperature in Fig. 3 coincide with anomalies in groundwater levels indicated in Fig. 4; that is, where there is a difference in temperature, a hydraulic gradient drop is also observed with a variation on the drop of $100 \mathrm{~m}$, and where there is also not a significant difference in temperature, there is no variation in hydraulic head.

\section{Discussion}

The objective of this work is to provide characteristics of the hydraulic behavior of the faults through the analysis by graphic correlation emphasizing that a graphical-correlation analysis offers an overview of the hydraulic behavior of the fault system when there is no detailed information. This graphical-correlation analysis was obtained from easy-access and measurement data such as temperature and the static groundwater level. In this work, only the Oriente fault was characterized for the study, due to a lack of information in characterizing minor failures. The effect on thermal and hydrogeologic anomalies across smaller individual faults is more difficult to assess, since it is necessary to have detailed data on both sides of the fault, and in this case, they were not available, and the sampling points are spaced too far apart to reconstruct the flow pattern near the fault. This could be part of a future analysis, since Bense et al. (2003) suggests that the set of minor faults may have a strong, thus cumulative, effect on the internal structure of the aquifer system due to an individual small-scale hydraulic effect in groundwater flow, thus, providing an anisotropic effect in the hydraulic conductivity to the regional level. It is likely that the sequence of unconsolidated sediments is cut by minor faults at shallow depths. However, deeper sediments may only be affected by active large faults such as the Oriente fault of the valley of Aguascalientes. This fault is one of the most prominent regional faults within the fault system of the Aguascalientes valley. Due to its geometric characteristics, we suspect that this fault has an impact on the hydrogeology of the local aquifer corroborated in the zones selected where the horizontal fluid is interrupted. The analysis presented here demonstrated that this fault presents thermal and hydraulic anomalies along its trace and showing the complex behavior of a barrier-conduit system.

\section{Conclusions}

It is concluded that, although the information of the wells that surround the metropolitan area is quite limited, the comparative analysis of parameters measured in the water gives an overview of the hydraulic behavior of the fault system within the Aguascalientes valley. In general, the faults can act as barriers or conduits to the horizontal flow of groundwater. A portion of the Oriente fault was analyzed and showed anomalies of the hydraulic head and water temperature across the fault. The first showed variations of up to $100 \mathrm{~m}$ and the second of $10^{\circ} \mathrm{C}$, respectively. Maximum variations of both parameters are present in the same areas of the analyzed portion. This hydraulic response is the first indication that the Oriente fault is overall behaving as a barrier system, at least in the study area, but it has some branches behaving as a conduit, mainly in the north, based on the smaller variation in the temperature and groundwater levels. It is also important to mention that no hydraulic impact of the subsidenceinduced small faults inside the valley was observed, but this probably has to do with the lack of data around these faults; therefore, additional monitoring points are required. As a result of the analysis, it can be concluded that the Oriente fault in the Aguascalientes valley may present hydraulic characteristics of a barrier-conduit system. It is important to mention that the graphical-correlation analysis gives an overview of the hydraulic behavior of the fault system, which instead may have important implications in the regional and local groundwater flow system.

Data availability. The measurements of temperature and hydraulic head from the wells are for public use in Mexico. However, it is necessary to officially request them from the Conagua (National Council of Water) within the State of Aguascalientes, Mexico. Unfortunately, those data are not included on its government page.

Author contributions. LGM managed the data collection, created the maps and figures, determined the zones, interpreted the obtained results, and wrote and arranged the paper. MHM gave guidance in the analysis and determination of the hydraulic behavior of the fault as well as in the creation of maps and their interpretation and revised the paper. AEMZ gave guidance in the analysis of the characterization of areas with the hydraulic behavior of a barrier or conduit and revised the paper.

Competing interests. The authors declare that they have no conflict of interest.

Special issue statement. This article is part of the special issue "TISOLS: the Tenth International Symposium On Land Subsidence - living with subsidence". It is a result of the Tenth International Symposium on Land Subsidence, Delft, the Netherlands, 17-21 May 2021.

Acknowledgements. The authors are thankful for the reviewer's comments, which significantly improved the quality of this paper, and the Conagua (National Council of Water) within the State of Aguascalientes, Mexico, for providing the information. 


\section{References}

Anderson, T. R. and Fairley, J. P.: Relating permeability to the structural setting of a fault-controlled hydrothermal system in southeast Oregon, USA, J. Geophys. Res., 113, B05402, https://doi.org/10.1029/2007JB004962, 2008.

Apaydin, A.: Relation of tectonic structure to groundwater flow in the Beypazari region, NW Anatolia, Turkey, Hydrogeol. J., 18, 1343-1356, https://doi.org/10.1007/s10040-010-0605-1, 2010.

Bense, V. F., Van den Berg, E. H., and Van Balen, R. T.: The impact of faults on the hydrogeological conditions in the Roer Valley Rift System: an overview, Neth. J. Geosci., 82, 41-54, https://doi.org/10.1017/S0016774600022782, 2003.

Bense, V. F., Pearson, M. A., Chaudhary, K., You, Y., Cremer, N., and Simon, S.: Thermal anomalies indicate preferential flow faults in unconsolidated sedimentary aquifers, Geophys. Res. Lett., 35, L24406, https://doi.org/10.1029/2008g1036017, 2008.

Caine, J. S., Evans, J. P., and Forster, C. B.: Fault zone architecture and permeability structure, Geology, 24, 1025-1028, https://doi.org/10.1130/00917613(1996)024<1025:FZAAPS>2.3.CO;2, 1996.

Conagua (Comisión Nacional del Agua): unpublished results, 2017.

Haneberg, W. C.: Steady-state groundwater flow across idealized faults, Water Resour. Res., 31, 1815-1820, https://doi.org/10.1029/95WR01178, 1995.

Hernández-Marín, M. and Burbey, T. J.: The role of faulting on surface deformation patterns from pumping-induced groundwater flow (Las Vegas Valley, USA), Hydrogeol. J., 17, 1859-1875, 2009.
Hernandez-Marín, M., Pacheco-Martinez, P., Burbey, T. J., Carreon-Freyre, D. C., Ochoa-Gonzalez, G. H., CamposMoreno, G. E., and Lira-Gomez, P.: Evaluation of subsurface infiltration and displacement in a subsidence-reactivated normal fault in the Aguascalientes Valley, Mexico, Environ. Earth Sci., 76, 812 pp., https://doi.org/10.1007/s12665-017-7163-y, 2017.

Hernández-Marín, M., Guerrero-Martínez, L., Zermeño-Villalobos, A., Rodríguez-González, L., Burbey, J. B., Pacheco-Martínez, J., Martínez-Martínez, S. I., and González-Cervantes, N.: Spatial and temporal variation of natural recharge in the semi-arid valley of Aguascalientes, Mexico, Hydrogeol. J., 26, 2811-2826, https://doi.org/10.1007/s10040-018-1819-x, 2018.

Pacheco-Martínez, J., Hernández-Marín, M., Burbey, T. J., González-Cervantes, N., Ortiz-Lozano, Á., ZermeñoDe-León, M., and Solís-Pinto, A.: Land subsidence and ground failure associated to groundwater exploitation in the Aguascalientes Valley, México, Engin. Geol., 164, 172-180, https://doi.org/10.1016/j.enggeo.2013.06.015, 2013.

Pacheco-Martínez, J., Cabral-Cano, E., Wdowinski, S., HernándezMarín, M., Ortiz-Lozano, J. A., and Zermeño-de-León, E. M.: Application of InSAR and Gravimetry for Land Subsidence Hazard Zoning in Aguascalientes, Mexico, Remote Sens., 7, 1703517050, https://doi.org/10.3390/rs71215868, 2015.

SIFAGG (Sistema de Información de Fallas Geológicas y Grietas): Secretaría de Obras Públicas del Gobierno del Estado de Aguascalientes, available at: http://www.aguascalientes.gob.mx/ sop/sifagg/web/mapa.asp, last access: 29 April 2017. 